\title{
Midkine expression is correlated with an adverse prognosis and is down-regulated by p53 in oral squamous cell carcinoma
}

\author{
KAZUTOSHI OTA ${ }^{1}$, HIROMI FUJIMORI ${ }^{2}$, MITSUHARU UEDA ${ }^{2}$, HIROFUMI JONO $^{2}$, SATORU SHINRIKI ${ }^{1}$, \\ TOMOKO OTA $^{1}$, TAKANAO SUEYOSHI ${ }^{3}$, MANABU TAURA ${ }^{4}$, AYAKA TAGUMA ${ }^{4}$, \\ HIROFUMI KAI ${ }^{4}$, MASANORI SHINOHARA ${ }^{1}$ and YUKIO ANDO ${ }^{2}$
}

\begin{abstract}
Departments of ${ }^{1}$ Oral and Maxillofacial Surgery, ${ }^{2}$ Diagnostic Medicine and ${ }^{3}$ Orthopedics, Graduate School of Medical Sciences, Kumamoto University, 1-1-1 Honjo, Kumamoto 860-8556; ${ }^{4}$ Department of Molecular Medicine,

Faculty of Medical and Pharmaceutical Sciences, Global COE Cell Fate Regulation Research and Education Unit, Kumamoto University, 5-1 Oe-honmachi, Kumamoto 862-0973, Japan
\end{abstract}

Received March 30, 2010; Accepted May 21, 2010

DOI: 10.3892/ijo_00000729

\begin{abstract}
Midkine (MK) expression has been documented to be inversely correlated with the prognosis of patients with various tumors, but the mechanism of this relationship has not been well characterized. Recent studies have also correlated p53 expression with prognosis of patients with oral squamous cell carcinoma (OSCC). We evaluated the relationship between MK expression and clinicopathological features of patients with OSCC to clarify the influence of p53 status on MK expression in OSCC cells. Our results showed that patients with MK over-expression in OSCC cells had a significantly lower 5-year survival rate compared with patients with low MK expression. Immunohistochemical analyses demonstrated overexpression of MK protein in OSCC samples with mutant p53. Cell culture experiments with human lingual squamous cell carcinoma revealed that the MK gene was regulated by the wild-type p53 gene. Thus, MK expression may affect prognosis via the p53 status and mutation of the p53 gene, and MK may be an attractive target for therapeutic intervention in patients with cancer cells with mutant p53.
\end{abstract}

\section{Introduction}

Oral cancer is one of the most common types of human cancer worldwide (1). Oral squamous cell carcinoma (OSCC) comprises at least $90 \%$ of all oral malignancies (2). The prognosis for patients with OSCC is still not good despite better diagnostic techniques and treatment innovations.

Correspondence to: Professor Yukio Ando, Department of Diagnostic Medicine, Graduate School of Medical Sciences, Kumamoto University, 1-1-1 Honjo, Kumamoto 860-8556, Japan E-mail: andoy709@kumamoto-u.ac.jp

Key words: midkine, prognosis, p53, oral squamous cell carcinoma, immunohistochemistry
Improved survival of patients with OSCC requires better methods for prediction of prognosis and novel therapies that focus on molecular targets.

Several oncogenes and tumor suppressor genes were previously implicated in the pathogenesis of various cancers (3-7). Midkine (MK) is a novel heparin-binding growth factor found as a product of a retinoic acid-responsive gene (8). MK has been reported to be intensely expressed in various human tumors including lung (9), breast (10), gastric (11), colorectal (12), esophageal (13), liver (14), thyroid (15), prostate (16) and pancreatic (17). In addition, MK expression has been correlated with poor prognosis in patients with neuroblastomas (18), astrocytomas (19), pancreatic cancers (17) and gastrointestinal stromal tumors (20). In a previous study, MK expression was increased in blood samples from OSCC patients and was associated with prognosis (as assessed by 5-year survival) but not with other conventional prognostic factors such as clinical stage, tumor size and cervical lymphnode metastasis (21). That report suggested that the mechanism of the association of MK with prognosis was different from that for tumor proliferation and metastasis. MK expression has been demonstrated to have a significant relationship with drug resistance, which may be involved in influencing prognosis in OSCC. Kato et al (22) recently reported that the intensity of p53 immunoreactivity was strongly correlated with prognosis and that no significant relationship between p53 expression and other clinicopathological parameters was found in OSCC. In addition, the p53 tumor suppressor gene has been documented to contribute to drug resistance (23). We thus hypothesized that a pathway of communication between MK and p53 may exist. In this study, we analyzed MK expression in OSCC tissues and examined its relationship to clinicopathological data. Furthermore, we investigated whether MK expression could be regulated by p53 in OSCC cells.

\section{Materials and methods}

Patients and samples. A total of 113 primary OSCC specimens were collected from patients who underwent radical 
treatment at the Department of Oral and Maxillofacial Surgery, Kumamoto University Hospital. We excluded patients who presented with distant metastases. We also collected four normal oral mucosal specimens, which we excised surgically during tooth extractions. Biopsy and normal specimens were either flash frozen in liquid nitrogen and stored at $-80^{\circ} \mathrm{C}$ or fixed in $10 \%$ formaldehyde solution and embedded in paraffin. We obtained informed consent from all patients. All OSCC patients were staged according to the 1997 UICC TNM Classification of Malignant Tumours (24). Clinicopathological data, including age, sex, tumor size, cervical lymph node metastasis, degree of differentiation of OSCC and prognosis, were obtained from patient files.

Western blot analysis. To assess the expression of MK in OSCC and oral mucosal samples, Western blot analysis was performed. The samples were homogenized in lysis buffer (M-PER mammalian protein extraction reagent; Pierce, Rockford, IL, USA) containing protease inhibitors (Protease Inhibitor Cocktail; Nacalai Tesque Inc., Kyoto, Japan). Samples that contained $400 \mu \mathrm{g}$ of protein were diluted with phosphate-buffered saline (PBS) to $1 \mathrm{ml}$ and were incubated on ice for $1 \mathrm{~h}$ with $50 \mu \mathrm{l}$ of $50 \%$ heparin-Sepharose gel (Heparin Sepharose CL-6B; GE Healthcare, Buckinghamshire, England). The gels were washed 3 times with PBS, and heparin-Sepharose-bound molecules were eluted with $25 \mu 1$ of electrophoresis sample buffer at $95^{\circ} \mathrm{C}$ for $5 \mathrm{~min}$. Samples were loaded onto a $15 \%$ SDS-polyacrylamide gel and were transferred to pure nitrocellulose membranes (Bio-Rad Laboratories, Hercules, CA, USA). The membranes were blocked with $5 \%$ skim-milk in PBS containing $0.1 \%$ Tween-20. The rabbit monoclonal anti-human MK antibody diluted 1:2000 and horseradish peroxidase-conjugated goat anti-rabbit IgG antibody diluted 1:2000 were used as primary and secondary antibodies, respectively. For an internal control, an antibody against B-actin (AC-15; Sigma-Aldrich, St. Louis, MO, USA), diluted 1:2000, was used. The immunocomplex was visualized by means of the $\mathrm{ECL}^{+}$Western blotting detection system (GE Healthcare) according to the manufacturer's instructions. For quantification of MK expression, we calculated the density and dimension of the bands by using a computer graphic analytical software (LAS-4000 mini EPUV; Fujifilm, Tokyo, Japan).

Immunohistochemistry (IHC). Paraffin-embedded 4- $\mu$ m-thick sections were prepared, blocked with $0.3 \%$ hydrogen peroxide in methanol, and microwaved for $15 \mathrm{~min}$. After being incubated with Protein Block serum-free (Dako, Glostrup, Denmark), sections were incubated overnight at $4^{\circ} \mathrm{C}$ with mouse monoclonal anti-human MK antibody (IP14), which was provided by Cell Signals Inc. (Yokohama, Japan), and rabbit polyclonal anti-human p53 antibody (RSP53; Nichirei Corp., Tokyo, Japan) (MK dilution 1:100, p53 dilution 1:1000). After a 30-min incubation with anti-mouse labeled polymer (EnVision ${ }^{+}$System HPR; Dako), 3,3'-diaminobenzidine was used as the chromogen. Sections were counterstained with hematoxylin to enhance nuclear detection.

MK immunoreactivity was assessed independently, in a blinded fashion, by two observers, with consensus achieved for all 93 tumors. MK expression was categorized into four
(A)

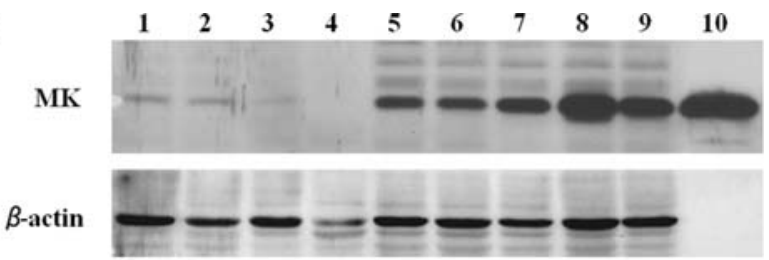

(B)

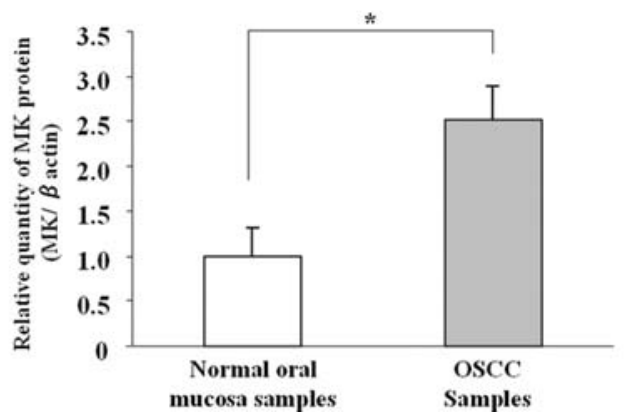

Figure 1. (A) Western blot analysis for MK expression in OSCC samples. Lanes 1-3, normal oral mucosa, and lanes 5-9, OSCC samples. (B) Quantitative evaluation of normal oral mucosa and OSCC samples by Western blot analysis using the analysis software. The statistical significance was evaluated using Student's t-test. ${ }^{*} \mathrm{p}<0.005$.

stages on the basis of the percentage of positive cells, with scores as follows: negative (score points 0 ): $<5 \%$ of cells positive; weak (score points 1): 6-30\% of cells positive; moderate (score points 2): $31-60 \%$ of cells positive; and strong (score points 3): $>61 \%$ of cells positive. OSCC samples were recorded as overexpressing $\mathrm{MK}$ when $>30 \%$ of the tumor cells (MK scores of 3 and 4) exhibited immunoreactivity. For p53 expression, cases with $>5 \%$ of positively stained tumor cells were defined as positive.

Cell culture and treatments. Human lingual SCC cells (SAS and HSC-4) were obtained from the Cell Resource Center for Biomedical Research, Tohoku University (Sendai, Japan). These cells were maintained in RPMI-1640 medium (Gibco, Grand Island, NY, USA), supplemented with $10 \%$ heatinactivated fetal bovine serum (FBS) (Gibco), at $37^{\circ} \mathrm{C}$ in $5 \%$ $\mathrm{CO}_{2}$. On the day before the experiments were performed, cells were seeded at a density of $5 \times 10^{5}$ cells per $35-\mathrm{mm}$ tissue culture dish. Either an empty vector (as the control) or the wild-type p53 expression plasmid (pCDM8-p53), which was cloned into the pCDM8 expression vector (25), was transfected by using Lipofectamine 2000 (Invitrogen, Carlsbad, CA, USA) according to the manufacturer's protocol. Lipofectamine 2000 diluted in Opti-MEM (Gibco) was mixed with total DNA at a ratio of 1:4 (DNA-Lipofectamine 2000) and was applied to subconfluent cells in RPMI-1640 medium with $10 \%$ FBS. As the small interfering RNA (siRNA) for p53, a Silencer Validated siRNA targeting human p53 (Ambion/Applied Biosystems, Foster City, CA, USA) and a Silencer Negative Control no. 1 siRNA (Ambion/ Applied Biosystems) for the control siRNA were used. siRNA for p53 was transfected into SAS cells by using Lipofectamine 2000 according to the manufacturer's instructions. p53 siRNA (25 pmol, diluted in Opti-MEM) and control siRNA ( 25 pmol, diluted in Opti-MEM) in $500 \mu 1$ of medium were transfected into $50 \%$ confluent cells to knock-down p53 


\section{a}

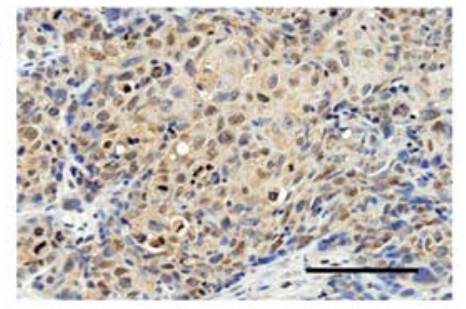

c

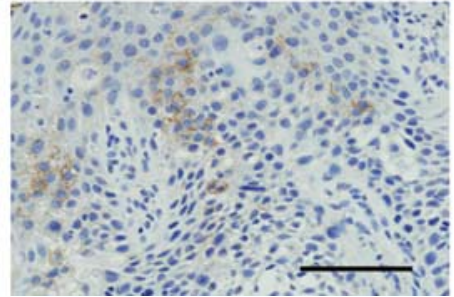

b

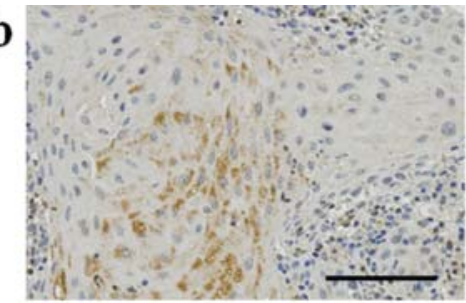

d

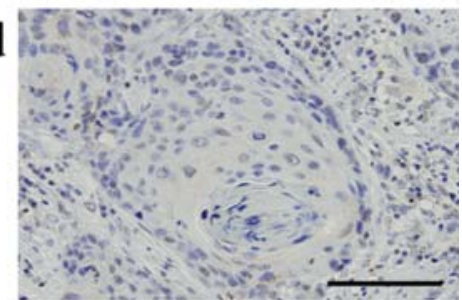

Figure 2. MK immunohistochemistry in OSCC samples. (A) Strong (score 3): 100-61\% for MK expression, (B) moderate (score 2): 60-31\% for MK expression, (C) weak (score 1): 30-5\% for MK expression, and (D) negative (score 0): lower 5\% for MK expression (A) to (D): original magnifications, x200, bars $=200 \mu \mathrm{m}$.

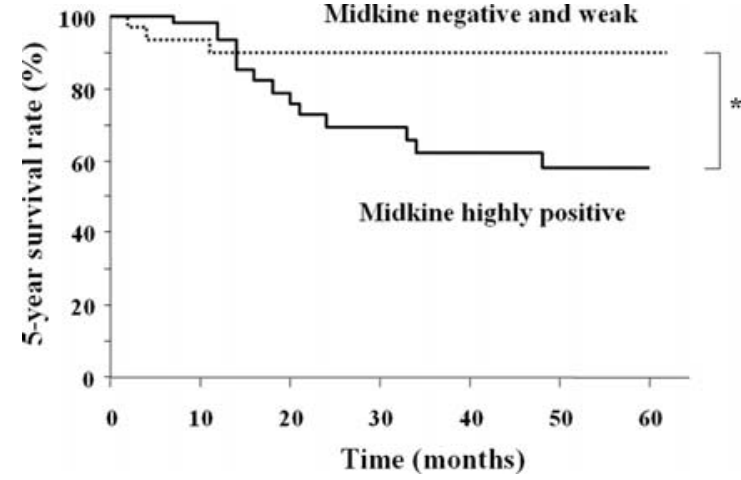

Figure 3. Survival rate of OSCC patients with high or low MK immunoreactivity. Dotted line: five-year survival rate of patients with MK immunoreactivity of 0 and $1 \mathrm{MK}$ score $(\mathrm{n}=31)$, and black line: that of patients with MK immunoreactivity of 3 and $4 \mathrm{MK}$ score $(n=62)$. The statistical significance was evaluated using log-rank test. ${ }^{*} \mathrm{p}<0.05$.

gene expression. Cells were moved to serum-free RPMI-1640 medium at $5 \mathrm{~h}$ after transfection and were harvested at $36 \mathrm{~h}$ after transfection.

$R N A$ isolation and real-time PCR. Total RNA was extracted from cells by using TRIzol (Invitrogen) and was reverse transcribed to cDNA by using the ExScript RT reagent (Takara Bio Inc., Otsu, Japan). All PCR reactions were performed via the LightCycler 480 System (Roche Diagnostics, Basel, Switzerland) with a LightCycler 480 SYBR-Green I Master kit (Roche Diagnostics). The following conditions were used for each reaction: initialization for $10 \mathrm{sec}$ at $95^{\circ} \mathrm{C}$ and then 45 cycles of amplification, with $5 \mathrm{sec}$ at $95^{\circ} \mathrm{C}$ for denaturation, and $20 \mathrm{sec}$ at $60^{\circ} \mathrm{C}$ for annealing and elongation. After amplification, the temperature was slowly raised to above the melting temperature of the PCR product to measure fluorescence and thereby to determine the melting curve. The primers used for real-time PCR were as follows: p53 forward: 5'-ACT AAGCGAGCACTGCCCAAC-3', p53 reverse: 5'-CCTCAT TCAGCTCTCGGAACATC-3'; MK forward: 5'-AAGGCGC GCTACAATGCTC-3', MK reverse: 5'-CATCCAGGCTTG
GCGTCTA-3'; ß-actin forward: 5'- TGGCACCCAGCACAA TGAA-3', and B-actin reverse: 5'-CTAAGTCATAGTCCGC CTAGAAGCA-3'. The threshold cycle values for each gene amplification cycle were normalized by subtracting the threshold cycle value calculated for the $\beta$-actin gene. Normalized gene expression values were expressed as the relative quantity of gene-specific mRNA. All standards and samples were analyzed in triplicate.

Statistical analyses. The Shapiro-Wilk test was used for normality of data, after which data were evaluated via Student's t-test and analysis of variance (for normal distributed data) or via the Kruskall-Wallis test (for non-normal data). Survival curves were plotted by using the Kaplan-Meier method and were analyzed with the log-rank test for univariate analysis. All analyses were performed with the JMP IN Version 5.1 (SAS Institute Japan, Tokyo, Japan). p $<0.05$ was considered statistically significant.

\section{Results}

MK expression and its correlation with prognosis in OSCC. Fig. 1 shows the results of Western blot analysis for MK expression in normal oral mucosa and OSCC samples. Quantitative evaluation with the computer graphic software revealed higher intensity bands corresponding to MK protein in five OSCC samples but not in normal oral mucosa samples.

According to IHC, MK expression was localized in the cytoplasm and some nuclei in OSCC cells (Fig. 2). The immunoreactive intensity of MK protein in 93 OSCC samples was semiquantitatively evaluated: 32 showed strong reactions; 30, moderate reactions; and 19, weak reactions. Twelve had no reaction (negative). Statistical analysis of the MK points scored according to IHC results indicated no significant correlations with the clinicopathological factors of tumor size, cervical lymph node metastasis and pathological differentiation (Table I). However, OSCC patients with low MK scores (negative and weak) had a significantly greater 5-year survival rate than did those with high MK scores (strong and moderate) (90.0 vs. 57.7\%; p<0.05) (Fig. 3). 
Table I. Relationship between clinical parameters and MK scores in patients with OSCC.

\begin{tabular}{|c|c|c|c|}
\hline Clinical parameters & No. of patients & MK protein $($ MK score points \pm SD) & p-values \\
\hline \multicolumn{4}{|l|}{ Sex } \\
\hline Male & 54 & $1.85 \pm 1.09$ & \multirow[t]{2}{*}{0.610} \\
\hline Female & 39 & $1.91 \pm 1.00$ & \\
\hline \multicolumn{4}{|l|}{ Age (years) } \\
\hline$<60$ & 24 & $1.83 \pm 1.09$ & \multirow[t]{2}{*}{0.604} \\
\hline$\geq 60$ & 69 & $1.90 \pm 1.02$ & \\
\hline \multicolumn{3}{|l|}{ Clinical stage } & \multirow[t]{3}{*}{0.498} \\
\hline I-II & 34 & $1.88 \pm 0.95$ & \\
\hline III-IV & 59 & $1.88 \pm 1.08$ & \\
\hline \multicolumn{4}{|l|}{ Tumor size (mm) } \\
\hline$<40$ & 54 & $1.91 \pm 0.99$ & \multirow[t]{2}{*}{0.380} \\
\hline$\geq 40$ & 39 & $1.84 \pm 1.10$ & \\
\hline \multicolumn{4}{|l|}{$\begin{array}{l}\text { Cervical lymph node } \\
\text { metastasis ( } \mathrm{N} \text { factor) }\end{array}$} \\
\hline $\mathrm{N}(-)$ & 49 & $1.78 \pm 0.98$ & \multirow[t]{2}{*}{0.852} \\
\hline $\mathrm{N}(+)$ & 44 & $2.00 \pm 1.08$ & \\
\hline \multicolumn{4}{|l|}{ OSCC differentiation } \\
\hline Well & 59 & $1.76 \pm 1.04$ & \multirow[t]{3}{*}{0.329} \\
\hline Moderately & 25 & $2.12 \pm 0.97$ & \\
\hline Poorly & 9 & $2.00 \pm 1.12$ & \\
\hline
\end{tabular}

Relationship between $M K$ and p53 immunoreactivity in OSCC tissues. IHC demonstrated positive p53 immunoreactivity in 58 of 93 cases $(62.4 \%)$. Positive p53 staining in OSCC samples occurred not only in cancer cells but also in part of the basal mucosal layers in epithelial dysplasia. Mutant p53 proteins have longer half-lives than wild-type protein and tend to be detected by IHC, so we also exa-mined samples for p53 gene mutations $(26,27)$. Fifty-eight of 93 samples showed such mutations. When we compared the immunoreactive association of p53 with MK in OSCC, when MK immunoreactivity was positive, the localization patterns of those immunoreactive proteins were similar (Fig. 4). MK scores in p53-positive samples and those in p53-negative samples were $2.21 \pm 0.89$ and $1.39 \pm 1.02$, respectively. A statistically significant correlation was thus observed between MK points and p53-positive and p53-negative samples $(\mathrm{p}<0.001)$ (Fig. 4B).

Effect of p53 gene transfection and inhibition on MK expression in OSCC cell lines. Because MK overexpression was strongly related to p53 mutation, we used pCDM8-p53 and p53 siRNA to assess the effect of p53 gene transfection and inhibition, respectively, on MK expression in OSCC cell lines. Although both pCDM8-p53-transfected SAS cells and HSC-4 cells evidenced increased p53 mRNA levels, the p53 gene transduction efficiency in HSC-4 cells with a p53 dominant-negative mutation (codon 248) was much lower than that in SAS cells. In p53-transfected cells, MK mRNA significantly decreased in SAS cells compared with empty vector-transfected cells, whereas that in HSC-4 cells did not change significantly (Fig. 5A and B).

We also analyzed the MK mRNA level by knocking down p53 by using siRNA in SAS cells. After transfection, p53 mRNA levels significantly decreased, and MK mRNA levels significantly increased compared with levels of control cells (Fig. 5C).

\section{Discussion}

In this report, we demonstrated that $\mathrm{MK}$ overexpression in OSCC tissues led to a worse prognosis and that this MK overexpression occurred in p53 mutant cancer cells. We also confirmed that MK expression was regulated by expression of p53 in OSCC cell cultures. MK has been well documented to play important roles in the survival $(28-30)$, growth $(31,32)$, and migration (33-35) of many cells, which may contribute to oncogenesis and tumor progression. Therefore, it was not surprising to find MK overexpression in various tumors and that it was related to prognosis. Our analyses revealed significantly higher MK expression in OSCC samples than in normal mucosa samples. However, our results also indicated that expression of MK protein was not related to clinical stage, tumor size, or cervical lymph node metastasis in OSCC patients. Nevertheless, patients with high MK scores as evaluated by IHC had a significantly lower 5-year survival rate compared with patients with low MK scores $(\mathrm{p}<0.05)$. These results support findings from our previous study, indicating that S-MK concentrations may be a useful marker 
(A)

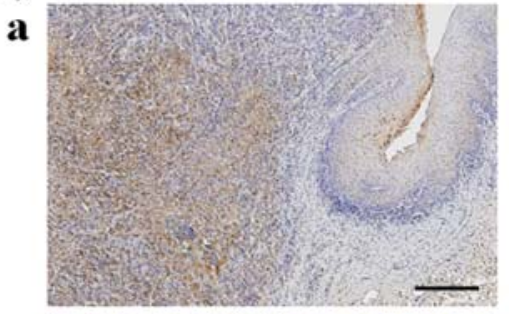

c

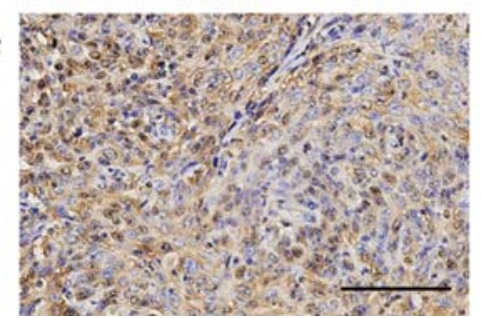

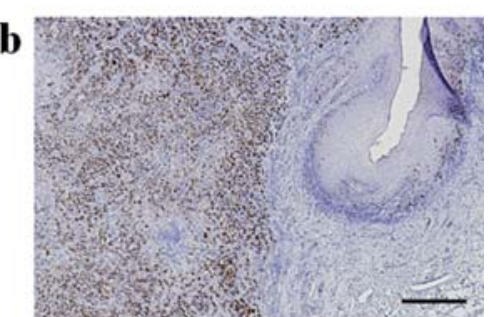

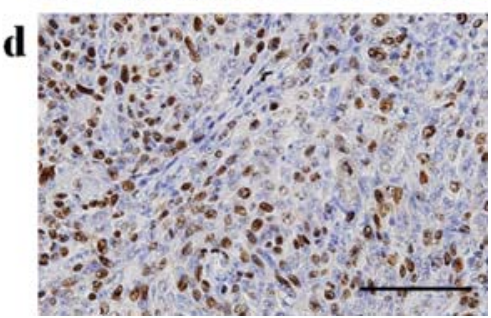

(B)

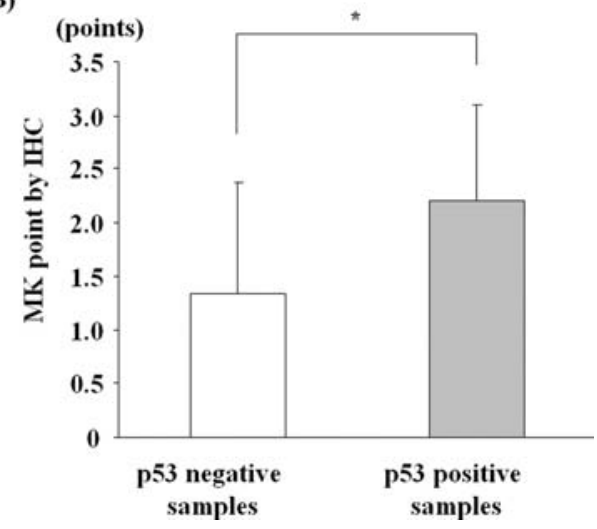

for predicting prognosis of OSCC patients (21). Ruan et al (36) also reported that high MK expression in OSCC samples confirmed by IHC was significantly correlated with poorer clinical outcome, and the level of MK expression was correlated with tumor size and stage. However, in gastrointestinal stromal tumors (20) and pancreatic head carcinoma (17), MK protein expression determined by IHC was correlated with a poor prognosis but had no relationship to tumor size and lymph node metastasis. With regard to analysis of serum MK concentrations, similar results were obtained for esophageal squamous cell carcinoma (37) and endometrial carcinoma (38). These findings lead us to theorize that MK expression may serve a dominant function in prognosis, with the mechanisms for tumor proliferation and metastasis being different.

Recent studies revealed that MK contributes to in anticancer drug resistance. Qi et al (30) reported that MK had cytoprotective activity, in that cisplatin (CDDP) induced apoptotic cell death through enhancement of Bcl-2 expression in both murine kidney and cultured Wilms' tumor cells (G401 cells). Mirkin et al (39) reported that MK indirectly mediated intercellular cytoprotective signals that originated from cells with acquired drug resistance to protect neighboring drug-sensitive cells and contribute to development of resistance to chemotherapy. In addition, Kang et al (40) used microarray analysis to perform global gene expression analysis of gastric cancer cell lines with acquired drug resistance to 5-fluorouracil, doxorubicin and CDDP. They reported that MK was an important factor related to drug resistance in all drugresistant cell lines. They described a strong contribution of MK to multidrug resistance in gastric cancer cells. In that study, all patients were treated with S-1 (TS-1; Taiho Pharmaceutical, Tokyo, Japan) adjuvant chemotherapy after curative surgery and radiotherapy. Thus, we also believed that MK could be associated with prognosis, presumably through a drug resistance mechanism. Further studies are needed, however, to clarify the relationship between drug sensitivity of OSCC and MK expression.

Many studies have instead focused on p53, a major tumor suppressor gene, which has an important role in apoptosis induction and contributes strongly to chemotherapy and radiotherapy resistance. With regard to prognosis, numerous studies have used the meta-analytical approach. Statistically significant differences were observed between p53 alterations and poor prognosis in various cancers (41-44). Moreover, Kato et al (22) reported that p53-positive immunoreactivity was manifested at the invasive front of OSCC, and concluded that p53 was an indicator of prognosis, even though the correlation between expression of $\mathrm{p} 53$ protein and clinicopathological findings was not significant. Those findings suggested that $\mathrm{p} 53$ gene alteration and MK gene expression may have a similar function in apoptosis and drug resistance. We thus suspected that the interaction between these genes may be important and hypothesized that one MK expression pathway is regulated by p53 gene. This hypothesis was supported by our findings: OSCC samples lacking p53 function, caused by a p53 gene mutation, had increased MK protein expression as confirmed by IHC. In vitro studies revealed that $\mathrm{p} 53$ gene overexpression, as resulting from 

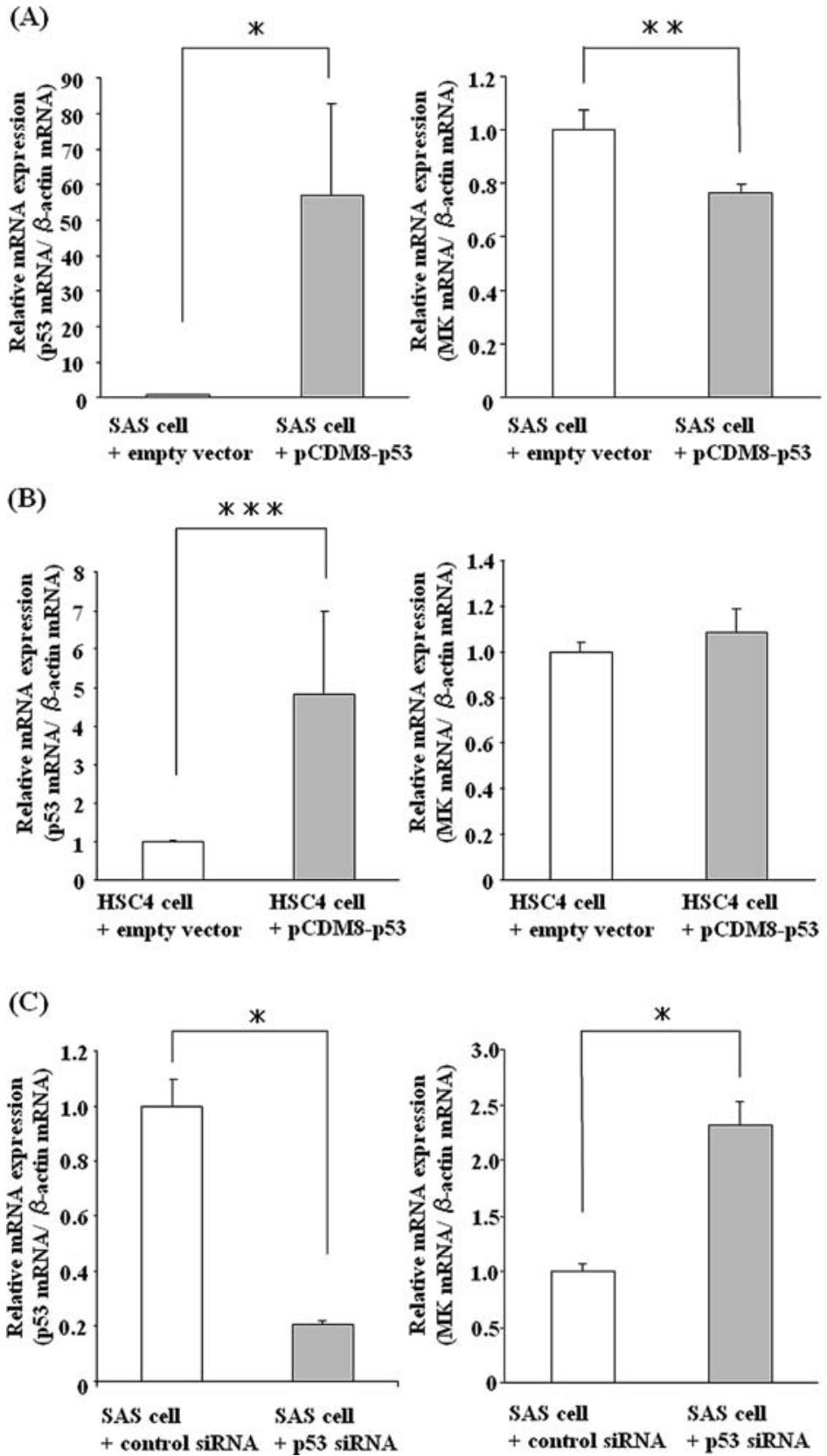

Figure 5. (A) Effect of p53 gene transfection on MK expression in SAS cells. (B) Effect of p53 gene transfection on MK expression in HSC-4 cells. (C) Effect of 553 gene inhibition using siRNA on MK expression in SAS cells. The statistical significance was evaluated using Student's t-test. ${ }^{*} \mathrm{p}<0.001,{ }^{* *} \mathrm{p}<0.01$, ${ }^{* * *} \mathrm{p}<0.05$

gene transfection, facilitated reduced MK gene expression in SAS cells, which had the wild-type p53 gene. HSC-4 cells, with a mutant p53 gene in DNA-binding domains and a dominant-negative effect, did not show significant effects on MK gene expression (Fig. 5A and B). As Fig. 5C indicates, p53 gene inhibition by siRNA increased MK gene expression, which clearly supported our hypothesis.

Previous studies of MK were mainly concerned with various physiological and pathological mechanisms, but the signals and mechanisms regulating MK expression were not well understood. Expression of MK was, however, found to be activated by the wt 1 Wilms' tumor gene (45) and nuclear factor $-\kappa \mathrm{B}(\mathrm{NF}-\kappa \mathrm{B})(46,47)$. Reynolds et al reported that hypoxia-inducible factor- $1 \alpha$ (HIF-1 $\alpha$ ) (through hypoxia) (48) and thyroid transcription factor-1 (TTF-1) (49) up-regulated MK expression. Because p53 is well known to contribute to expression of NF-KB and HIF-1 1 , p53 may also control MK expression indirectly via these transcription factors. Yu et al (50) also used the MK promoter-mediated luciferase assay and discovered that transcriptional activity of the MK promoter was regulated by the p53-dependent pathway. Thus, MK could be regulated by p53, either directly or indirectly.

With regard to human drug-resistant cancer (51-54) and advanced cancer $(55,56)$, adenovirus-mediated wild-type p53 gene transfer treatment was performed and produced a good response. However, the efficacy of this treatment depends on the p53 gene status of the target tumor cells. In p53 mutant cells, which have a dominant-negative function, 
this treatment has no benefit. Therefore, MK may become a new target gene only if MK strongly contributes to drug resistance downstream of the $\mathrm{p} 53$ pathway.

In conclusion, MK proteins were highly expressed and were designated as an independent prognostic factor in patients with OSCC. MK expression possessed a strong relationship with p53 gene status, and MK gene expression was regulated by the p53 gene. These results may lead to trials to inhibit MK expression by using an MK antibody and siRNA against drug-resistant cancer. Future studies of MK may elucidate anticancer drug resistance and contribute to improvement in prognosis of various cancers.

\section{Acknowledgements}

We are grateful to Cell Signals Inc. for donating midkine antibodies. The authors' work was supported by Grants-inAid for scientific research (B) 17390254 (Y. Ando) and (B) 17390541 (M. Shinohara) from the Ministry of Education, Science, Sports and Culture of Japan.

\section{References}

1. Casiglia J and Woo SB: A comprehensive review of oral cancer. Gen Dent 49: 72-82, 2001.

2. Beenken SW and Urist MM: Head and neck tumors. In: Current Surgical Diagnosis \& Treatment. Lange Medical Books/McGrawHill, New York, 2003.

3. Osman I, Drobnjak M, Fazzari M, Ferrara J, Scher HI and Cordon-Cardo C: Inactivation of the p53 pathway in prostate cancer: impact on tumor progression. Clin Cancer Res 5: 2082-2088, 1999.

4. Pfister C, Larue H, Moore L, et al: Tumorigenic pathways in low-stage bladder cancer based on p53, MDM2 and p21 phenotypes. Int J Cancer 89: 100-104, 2000.

5. Koontongkaew S, Chareonkitkajorn L, Chanvitan A, Leelakriangsak $\mathrm{M}$ and Amornphimoltham P: Alterations of p53, $\mathrm{pRb}$, cyclin $\mathrm{D}(1)$ and cdk4 in human oral and pharyngeal squamous cell carcinomas. Oral Oncol 36: 334-339, 2000.

6. Roskoski R Jr: The ErbB/HER receptor protein-tyrosine kinases and cancer. Biochem Biophys Res Commun 319: 1-11, 2004.

7. Reuter CW, Morgan MA and Eckardt A: Targeting EGFreceptor-signalling in squamous cell carcinomas of the head and neck. Br J Cancer 96: 408-416, 2007.

8. Kadomatsu K, Tomomura M and Muramatsu T: cDNA cloning and sequencing of a new gene intensely expressed in early differentiation stages of embryonal carcinoma cells and in midgestation period of mouse embryogenesis. Biochem Biophys Res Commun 151: 1312-1318, 1988.

9. Garver RI Jr, Chan CS and Milner PG: Reciprocal expression of pleiotrophin and midkine in normal versus malignant lung tissues. Am J Respir Cell Mol Biol 9: 463-466, 1993.

10. Garver RI Jr, Radford DM, Donis-Keller H, Wick MR and Milner PG: Midkine and pleiotrophin expression in normal and malignant breast tissue. Cancer 74: 1584-1590, 1994.

11. Aridome K, Tsutsui J, Takao S, et al: Increased midkine gene expression in human gastrointestinal cancers. Jpn J Cancer Res 86: 655-661, 1995

12. Ye C, Qi M, Fan QW, et al: Expression of midkine in the early stage of carcinogenesis in human colorectal cancer. Br J Cancer 79: 179-184, 1999

13. Miyauchi M, Shimada H, Kadomatsu K, et al: Frequent expression of midkine gene in esophageal cancer suggests a potential usage of its promoter for suicide gene therapy. Jpn J Cancer Res 90: 469-475, 1999.

14. Kato M, Shinozawa T, Kato S, Awaya A and Terada T: Increased midkine expression in hepatocellular carcinoma. Arch Pathol Lab Med 124: 848-852, 2000.

15. Kato M, Maeta H, Kato S, Shinozawa T and Terada T: Immunohistochemical and in situ hybridization analyses of midkine expression in thyroid papillary carcinoma. Mod Pathol 13: 1060-1065, 2000.
16. Konishi N, Nakamura M, Nakaoka S, et al: Immunohistochemical analysis of midkine expression in human prostate carcinoma. Oncology 57: 253-257, 1999.

17. Maeda S, Shinchi H, Kurahara H, et al: Clinical significance of midkine expression in pancreatic head carcinoma. Br J Cancer 97: 405-411, 2007.

18. Nakagawara A, Milbrandt J, Muramatsu T, et al: Differential expression of pleiotrophin and midkine in advanced neuroblastomas. Cancer Res 55: 1792-1797, 1995.

19. Mishima K, Asai A, Kadomatsu K, et al: Increased expression of midkine during the progression of human astrocytomas. Neurosci Lett 233: 29-32, 1997.

20. Kaifi JT, Fiegel HC, Rafnsdottir SL, et al: Midkine as a prognostic marker for gastrointestinal stromal tumors. J Cancer Res Clin Oncol 133: 431-435, 2007.

21. Ota K, Fujimori H, Ueda M, et al: Midkine as a prognostic biomarker in oral squamous cell carcinoma. Br J Cancer 99: 655-662, 2008.

22. Kato K, Kawashiri S, Tanaka A, et al: Predictive value of measuring p53 labeling index at the invasive front of oral squamous cell carcinomas. Pathol Oncol Res 14: 57-61, 2008.

23. O'Connor PM, Jackman J, Bae I, et al: Characterization of the p53 tumor suppressor pathway in cell lines of the national cancer institute anticancer drug screen and correlations with the growth-inhibitory potency of 123 anticancer agents. Cancer Res 57: 4285-4300, 1997.

24. Sobin LH and Wittekind C: TNM classification of malignant tumours. 6th edition. Wiley-Liss, New York, 2002.

25. Tamura T, Aoyama N, Saya H, et al: Induction of Fas-mediated apoptosis in p53-transfected human colon carcinoma cells. Oncogene 11: 1939-1946, 1995.

26. Finlay CA, Hinds PW, Tan TH, Eliyahu D, Oren M and Levine AJ: Activating mutations for transformation by $\mathrm{p} 53$ produce a gene product that forms an HSC70-p53 complex with an altered halflife. Mol Cell Biol 8: 531-539, 1988.

27. Iggo R, Gatter K, Bartek J, Lane D and Harris AL: Increased expression of mutant forms of p53 oncogene in primary lung cancer. Lancet 335: 675-679, 1990.

28. Michikawa M, Kikuchi S, Muramatsu H, Muramatsu T and Kim SU: Retinoic acid responsive gene product, midkine, has neurotrophic functions for mouse spinal cord and dorsal root ganglion neurons in culture. J Neurosci Res 35: 530-539, 1993.

29. Owada K, Sanjo N, Kobayashi T, et al: Midkine inhibits caspase-dependent apoptosis via the activation of mitogenactivated protein kinase and phosphatidylinositol 3-kinase in cultured neurons. J Neurochem 73: 2084-2092, 1999.

30. Qi M, Ikematsu S, Ichihara-Tanaka K, Sakuma S, Muramatsu T and Kadomatsu K: Midkine rescues Wilms' tumor cells from cisplatin-induced apoptosis: regulation of $\mathrm{Bcl}-2$ expression by midkine. J Biochem 127: 269-277, 2000.

31. Muramatsu H and Muramatsu T: Purification of recombinant midkine and examination of its biological activities: functional comparison of new heparin binding factors. Biochem Biophys Res Commun 177: 652-658, 1991.

32. Muramatsu H, Shirahama H, Yonezawa S, Maruta $H$ and Muramatsu T: Midkine, a retinoic acid-inducible growth/differentiation factor: immunochemical evidence for the function and distribution. Dev Biol 159: 392-402, 1993.

33. Takada T, Toriyama K, Muramatsu H, Song XJ, Torii S and Muramatsu T: Midkine, a retinoic acid-inducible heparinbinding cytokine in inflammatory responses: chemotactic activity to neutrophils and association with inflammatory synovitis. J Biochem 122: 453-458, 1997.

34. Maeda N, Ichihara-Tanaka K, Kimura T, Kadomatsu K, Muramatsu T and Noda M: A receptor-like protein-tyrosine phosphatase PTPzeta/RPTPbeta binds a heparin-binding growth factor midkine. Involvement of arginine 78 of midkine in the high affinity binding to PTPzeta. J Biol Chem 274: 12474-12479, 1999.

35. Horiba M, Kadomatsu K, Nakamura E, et al: Neointima formation in a restenosis model is suppressed in midkinedeficient mice. J Clin Invest 105: 489-495, 2000.

36. Ruan M, Ji T, Wu Z, Zhou J and Zhang C: Evaluation of expression of midkine in oral squamous cell carcinoma and its correlation with tumour angiogenesis. Int J Oral Maxillofac Surg 36: 159-164, 2007.

37. Shimada H, Nabeya Y, Tagawa M, et al: Preoperative serum midkine concentration is a prognostic marker for esophageal squamous cell carcinoma. Cancer Sci 94: 628-632, 2003. 
38. Tanabe K, Matsumoto M, Ikematsu S, et al: Midkine and its clinical significance in endometrial carcinoma. Cancer Sci 99: 1125-1130, 2008.

39. Mirkin BL, Clark S, Zheng X, et al: Identification of midkine as a mediator for intercellular transfer of drug resistance. Oncogene 24: 4965-4974, 2005.

40. Kang HC, Kim IJ, Park JH, et al: Identification of genes with differential expression in acquired drug-resistant gastric cancer cells using high-density oligonucleotide microarrays. Clin Cancer Res 10: 272-284, 2004.

41. Huncharek M, Kupelnick B, Geschwind JF and Caubet JF: Prognostic significance of p53 mutations in non-small cell lung cancer: A meta-analysis of 829 cases from eight published studies. Cancer Lett 153: 219-226, 2000.

42. Mitsudomi T, Hamajima N, Ogawa M and Takahashi T: Prognostic significance of p53 alterations in patients with nonsmall cell lung cancer: A meta-analysis. Clin Cancer Res 6: 4055-4063, 2000.

43. Steels E, Paesmans M, Berghmans T, et al: Role of p53 as a prognostic factor for survival in lung cancer: a systematic review of the literature with a meta-analysis. Eur Respir J 18: 705-719, 2001.

44. Pharoah PD, Day NE and Caldas C: Somatic mutations in the p53 gene and prognosis in breast cancer: A meta-analysis. Br J Cancer 80: 1968-1973, 1999.

45. Adachi Y, Matsubara S, Pedraza C, et al: Midkine as a novel target gene for the Wilms' tumor suppressor gene (wt1). Oncogene 13: 2197-2203, 1996.

46. Uehara K, Matsubara S, Kadomatsu K, Tsutsui J and Muramatsu T: Genomic structure of human midkine (MK), a retinoic acid-responsive growth/differentiation factor. J Biochem 111: 563-567, 1992.

47. You Z, Dong Y, Kong X, Beckett LA, Gandour-Edwards R and Melamed J: Midkine is a NF-kappaB-inducible gene that supports prostate cancer cell survival. BMC Med Genomics 1: 6, 2008 .
48. Reynolds PR, Mucenski ML, Le Cras TD, Nichols WC and Whitsett JA: Midkine is regulated by hypoxia and causes pulmonary vascular remodeling. J Biol Chem 279: 37124-37132, 2004.

49. Reynolds PR, Mucenski ML and Whitsett JA: Thyroid transcription factor (TTF)-1 regulates the expression of midkine (MK) during lung morphogenesis. Dev Dyn 227: 227-237, 2003.

50. Yu L, Ugai S, J OW, et al: Cell growth- and p53-dependent transcriptional activity of the midkine promoter confers suicide gene expression in tumor cells. Oncol Rep 10: 1301-1305, 2003.

51. Yu ZW, Zhao P, Liu M, et al: Reversal of 5-flourouracil resistance by adenovirus-mediated transfer of wild-type p53 gene in multidrug-resistant human colon carcinoma LoVo/5-FU cells. World J Gastroenterol 10: 1979-1983, 2004.

52. Eisold S, Linnebacher M, Ryschich E, et al: The effect of adenovirus expressing wild-type p53 on 5-fluorouracil chemosensitivity is related to p53 status in pancreatic cancer cell lines. World J Gastroenterol 10: 3583-3589, 2004.

53. Seth $\mathrm{P}$, Katayose $\mathrm{D}, \mathrm{Li} \mathrm{Z}$, et al: A recombinant adenovirus expressing wild-type p53 induces apoptosis in drug-resistant human breast cancer cells: A gene therapy approach for drugresistant cancers. Cancer Gene Ther 4: 383-390, 1997.

54. Gurnani M, Lipari P, Dell J, Shi B and Nielsen LL: Adenovirusmediated p53 gene therapy has greater efficacy when combined with chemotherapy against human head and neck, ovarian, prostate, and breast cancer. Cancer Chemother Pharmacol 44: 143-151, 1999.

55. Fujiwara T, Tanaka N, Kanazawa S, et al: Multicenter phase I study of repeated intratumoral delivery of adenoviral p53 in patients with advanced non-small-cell lung cancer. J Clin Oncol 24: 1689-1699, 2006

56. Nemunaitis J, Swisher SG, Timmons T, et al: Adenovirusmediated p53 gene transfer in sequence with cisplatin to tumors of patients with non-small-cell lung cancer. J Clin Oncol 18: 609-622, 2000 